\title{
Particle verbs are heads and phrases
}

\section{Jochen Zeller}

\section{Introduction ${ }^{1}$}

One of the most intriguing questions about particle verbs concerns the observation that they sometimes look like phrases and sometimes like heads. In this paper I suggest that particle verbs can in fact be represented by two different structures - they can appear either as complex $\mathrm{V}^{0} \mathrm{~s}$ consisting of the particle and the verb or alternatively as V'- or VP-nodes consisting of the verb and a phrasal particle complement.

Different aspects of grammar highlight different sides of the hybrid character of particle verbs. Table 1 lists some of the phenomena that illustrate the ambiguous behavior of the verb-particle construction:

\begin{tabular}{|l|l|l|}
\hline & pv looks like a $\mathrm{V}^{0}$ & pv looks like a VP \\
\hline verb movement & yes & yes \\
\hline inflection & no & yes \\
\hline verb movement to Comp & no & yes \\
\hline particle movement & ? & ? \\
\hline word formation & yes & no \\
\hline
\end{tabular}

Table 1: Phrasal and head-like properties of particle verbs

The paper is organized as follows. In section $2.1 \mathrm{I}$ discuss cases of verb movement in Dutch, English, and Norwegian that suggest that particle verbs can be both VPs and $\mathrm{V}^{0} \mathrm{~s}$ (row 1 in table 1). In section 2.2 I show that with respect to inflection, particle verbs exclusively show properties of VPs, since inflectional affixes always attach to the base verb, and not to the whole particle verb (row 2). The question why particle verbs never behave as complex heads when they move to Comp (row 3) is addressed in section 2.3. The topic of section 2.4 is the problematic status of particle movement (indicated by the question marks in row 4). Since particles can be phrasal complements, they are expected to undergo XPmovement, but as I show, particle movement is much more restricted than comparable movement of other phrasal complements of the verb.

In section 3 I investigate how the hybrid character of particle verbs can be captured theoretically. I discuss particle verbs from the perspective of three different frameworks, viz. the incorporation approach (Baker 1988), Parallel Morphology (Borer 1991; 1993) and Autolexical Syntax (Sadock 1985). Finally, I address the question of what distinguishes the (phrasal) representation of particle verbs from similar verb-complement constructions in section 4.

As shown by the fifth row in table 1 , the observation that particle verbs may provide the input to operations of further derivational morphology is often interpreted as evidence for the view that particle verbs are $\mathrm{V}^{0} \mathrm{~s}$. However, it is questionable whether this conclusion is

1. I thank the editors of this volume and two reviewers for their helpful comments and suggestions. 
justified. There is no one-to-one correspondence between syntactic heads and objects that can be the input to further word formation. For example, phrases can participate in compounding (cf. the who-is-who-question) and even in derivational morphology (cf. German Zurschaustellung, 'display', derived from zur Schau stellen, 'put on display'). I doubt that the word formation properties of a construction reveal anything about its syntactic representation; therefore I do not discuss word formation with particle verbs in this paper.

\section{The ambiguous status of particle verbs}

\subsection{Verb movement}

Compare the sentences from Norwegian and English in (1) and (2) with the Dutch examples in (3):

(1) a. Mannen har drukket opp vinnen the.man has drunk up the.wine

b. Mannen har drukket vinnen opp the.man has drunk the.wine up 'The man has drunk up the wine'

(Svenonius 1996: 10)

(2) a. John drank up his beer

b. John drank his beer up

(3) a. dat Jan zijn moeder wil opbellen that Jan his mother wants Prt-phone

b. dat Jan zijn moeder op wil bellen that Jan his mother Prt wants phone 'that Jan wants to call up his mother'

(Neeleman 1994: 24)

(1) and (2) show the familiar alternation known as particle shift. In the (a)-examples, the particle and the verb are adjacent; the (b)-examples show that the particle can be separated from the verb by an intervening direct object in English and Norwegian.

A similiar alternation is depicted in the so-called Verb Raising construction in (3). In Dutch Verb Raising, an embedded infinitive appears to the right of the matrix verb. ${ }^{2}$ If the infinitive is a particle verb, the particle and the verb can both appear adjacently to the right of the matrix verb, (3a). However, (3b) shows that the matrix verb can also intervene between the particle and the verb; like particle verbs in English and Norwegian, particle verbs in Dutch are separable.

It is traditionally assumed that in Verb Raising constructions, an embedded infinitival verb moves out of the embedded clause and adjoins to the right of the matrix verb (cf. Evers

2. Verb Raising of infinitives is triggered by modal, causative, raising and certain control verbs. Verb Raising can also occur with participles that undergo Verb Raising to the right of an auxiliary verb (see example (16) below). 
1975; van Riemsdijk 1978; Neeleman 1994). According to this view, (3a) involves verb movement of the particle verb as a unit, whereas in (3b), only the base verb has been moved, stranding the particle:

\section{(4) a. [ [ $\begin{array}{llll}\mathbf{t}_{\mathbf{i}} & ]\end{array}$ matrix verb [particle verb $\left.]_{\mathbf{i}}\right]$ \\ b. [[particle $\mathbf{t}_{\mathbf{i}}$ ] matrix verb verb $\mathbf{b}_{\mathbf{i}}$ ]}

Interestingly, particle shift also has been analyzed in terms of verb movement. For example, Johnson (1991) argues that NP-objects are generated to the right of the particle verb, but move to a specifier position to the left of the verb's base position in order to receive case. Importantly, Johnson argues that the verb also moves, to a position to the left of the landing site of the object. If the particle verb moves as a whole, we get (2a); if the particle is stranded, we get (2b) (for comparable analyses, see Larson 1988 and Neeleman this volume):

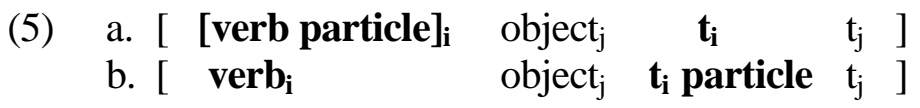

Comparing (4) and (5), we see that particle shift looks like the mirror image of Verb Raising of particle verbs - in both constructions, we either have movement of only the base verb or of the whole particle verb. Notwithstanding this similarity, and although both Verb Raising and particle shift have been treated extensively in the literature, nobody to my knowledge has ever explained the behavior of particle verbs with respect to particle shift in SVOlanguages like English and Norwegian and Verb Raising in an SOV-language like Dutch on the basis of a uniform treatment of particle verbs in these languages. ${ }^{3}$ This is particularly surprising in the light of another similarity between particle shift and particle verbs in Verb Raising constructions: The alternation shown in (5) is only licensed with particle verbs in English and Norwegian, and only particle verbs allow for the two options depicted in (4) in Dutch. Whereas prefix verbs cannot be separated in either Dutch or English, (6)-(7), phrasal complements of verbs cannot move with their verbs in these languages, (8)-(9) (I provide English data below; Norwegian patterns with English in the relevant respects, cf. Svenonius 1996):

(6) a. dat Jan tapijten $\mathrm{t}_{\mathrm{i}}$ wil $[\text { verkopen }]_{\mathrm{i}}$ that Jan carpets wants Pref-buy 'that Jan wants to sell carpets'

b. *dat Jan tapijten $\left[\right.$ ver- $\mathrm{t}_{\mathrm{i}}$ ] wil kopen $_{\mathrm{i}}$

3. For instance, Neeleman (1994) addresses both Verb Raising and particle shift. However, he explains separation of the particle verb in English not by leftward movement of the verb (as in Verb Raising), but by rightward movement of the particle. Furthermore, he claims that particle verbs in English are derived "syntactically”, whereas particle verbs in Dutch are derived "morphologically”. 
(7) a. Peter [outswam $]_{\mathrm{i}}$ his opponent $\mathrm{t}_{\mathrm{i}}$

b. *Peter $[\text { swam }]_{\mathrm{i}}$ his opponent [out- $\left.\mathrm{t}_{\mathrm{i}}\right]$

(8) a. dat hij naar Amsterdam $\mathrm{t}_{\mathrm{i}}$ wilde $[\text { vliegen }]_{\mathrm{i}}$ that he to Amsterdam wanted fly 'that he wanted to fly to Amsterdam'

b. *dat hij $\mathrm{t}_{\mathrm{i}}$ wilde [naar Amsterdam vliegen $]_{\mathrm{i}}$

(9) a. Peter gave $\mathrm{i}_{\mathrm{i}}$ the ring $\mathrm{t}_{\mathrm{i}}$ to Mary

b. *Peter [gave to Mary] $]_{\mathrm{i}}$ the ring $\mathrm{t}_{\mathrm{i}}$

The prepositions naar and to are transitive and therefore take arguments. One might suspect therefore that the PPs in (8) and (9) are too complex to form units with their verbs. However, even if the verb combines with an intransitive complement, the relevant verbcomplement-construction cannot appear as one unit to the right of a matrix verb in Dutch Verb Raising constructions or to the left of an NP-object in English. This is illustrated by (10) and (11) with respect to intransitive prepositions and in (12) and (13) with respect to adjectival resultative predicates: ${ }^{4}$

(10) a. dat Jan boven $\mathrm{t}_{\mathrm{i}}$ wil [wonen $]_{\mathrm{i}}$ that Jan upstairs wants live 'that Jan wants to live upstairs'

b. *dat Jan $\mathrm{t}_{\mathrm{i}}$ wil [boven wonen $]_{\mathrm{i}}$

(den Dikken 1995: 30)

(11) a. John took $\mathrm{i}_{\mathrm{i}}$ the garbage $\mathrm{t}_{\mathrm{i}}$ outside

b. *John [took outside $]_{\mathrm{i}}$ the garbage $\mathrm{t}_{\mathrm{i}}$

(12) a. dat Jan de deur [violet $\left.\mathrm{t}_{\mathrm{i}}\right]$ wil [verven $]_{\mathrm{i}}$ that Jan the door violet wants paint 'that Jan wants to paint the door violet'

b. *dat Jan de deur $\mathrm{t}_{\mathrm{i}}$ wil [violet verven $]_{\mathrm{i}} \quad$ (Neeleman 1994: 23)

(13) a. John [painted $]_{\mathrm{i}}$ the door [ $\mathrm{t}_{\mathrm{i}}$ green $]$

b. *John [painted green $]_{\mathrm{i}}$ the door $\mathrm{t}_{\mathrm{i}}$

(Neeleman 1994: 196)

Given the illustrated parallels between Dutch and English (and Norwegian), I propose to analyze both Verb Raising and particle shift in terms of verb movement and on the basis of

4. Some resultatives seem to be exceptional: they can undergo particle shift, (i), and can apparently move as complex units in Verb Raising constructions, (ii):
(i) John cut open the melon
(Neelman 1994, 195)
(ii) dat Jan de deur wil groen verven
(Neelman 1994, 23)

'that Jan wants to paint the door green'

The examples in (i) and (ii) suggest that these exceptions have to be analyzed along the same lines as particle verbs. Notice also that not all Dutch speakers accept examples like (ii) as grammatical. 
a theory of particle verbs that holds uniformly for languages like English, Norwegian, Dutch and German. I claim that particles (and only particles) can either move together with their verbs or can be stranded when the verb moves, and I argue that this follows from the fact that the verb-particle construction in both SOV- and SVO-languages can appear in two different forms. I assume that in examples where the verb moves and the particle is stranded, the particle verb is a verb-complement construction and patterns with the constructions in (8a)-(13a). The particle projects a phrase and hence cannot undergo movement together with the verb. If the particle verb moves as a whole, however, I claim that the particle and the verb form a complex verbal head which, like the verbs in (6) and (7), is inseparable.

The idea that particle verbs in English can appear as both heads and phrases has already been formulated in Baltin (1989) and Larson (1988). However, neither of these authors has used this assumption to account for the Verb Raising data in Dutch. This is what I attempt to do here. I assume that the observed behavior of particle verbs in Verb Raising and particle shift is explained by the same state of affairs, viz. by the fact that particle verbs can be realized as either heads or phrases.

There is well-known evidence from English and Norwegian that particle verbs can be represented as complex heads and as verb-complement constructions. (14) shows that certain particles can be modified with adverbs if the particle is stranded:
a. John threw the ball right in
b. Jon sparka hunden langt ut
Jon kicked the.dog far out
(English)
(Norwegian; Åfarli 1985: 76)

(14) follows from the assumption that separation of the verb and the particle is a result of the particle verb being a VP. In that case, the particle is a phrasal complement of the verb and an adverb can be located in its specifier or can be adjoined to the PrtP. But if adverbial modification is contingent on the particle being a phrase, then the proposal that the particle verb is a head when it precedes the object predicts that adverbial modification will be excluded here. This prediction is borne out. The adverbs in (15) cannot modify the particle if the particle verb moves as a whole:
(15) a. *John [threw right in] the ball
b. *Jon [sparka langt ut] hunden
Jon kicked far out the.dog
(English)
(Norwegian; Åfarli 1985: 76)

In Dutch Verb Raising constructions, a similar picture emerges. Certain postpositions can be reanalyzed as particles (cf. Groos 1989) and may undergo Verb Raising with the verb, (16a). Some of these elements can be modified by adverbs, (16b). However, the adverb is only licensed when the verb moves alone and leaves the particle behind, (16c):

(16) a. dat Jan de bal $\mathrm{t}_{\mathrm{i}}$ heeft [over geschoten $]_{\mathrm{i}}$ that Jan the ball has over shot 

b. dat Jan de bal vlak over $\mathrm{t}_{\mathrm{i}}$ heeft [geschoten $]_{\mathrm{i}}$ that Jan the ball right over has shot
c. *dat Jan de bal $\mathrm{t}_{\mathrm{i}}$ heeft [vlak over geschoten $]_{\mathrm{i}}$ that Jan the ball has right over shot

(den Dikken 1995: 108)

Again, the contrast between (16b) and (16c) suggests that particle verbs are heads when they move as units, but verb-complement constructions when only the verb moves. I henceforth assume that particle verbs can be realized either as VPs (the verb moves, the particle is a phrase and can be modified) or $\mathrm{V}^{0} \mathrm{~s}$ (the whole particle verb moves and no particle modification is possible). ${ }^{5}$

\section{$2.2 \quad$ Inflection}

One would expect that the dual status of particle verbs is reflected also by their inflectional properties. Unfortunately, this is not the case. In German and Dutch, the infinitival prefixes zu (German) and te (Dutch) normally precede verbs, including morphologically complex verbs like those in (17). However, the infinitival prefix always separates the particle from the verb, which shows that the inflectional affix is added directly to the base verb and never to the whole particle verb, (18):
a. zu verkaufen - *verzukaufen, 'sell'
b. te verkopen - *vertekopen, 'sell'
(German)
(Dutch)
a. an-zu-rufen
- *zu anrufen, 'call up’
(German)
b. op te bellen
- *te opbellen, 'call up'
(Dutch)

A similar fact can be observed in English with respect to inflectional suffixes. For example, the past tense morpheme -ed is attached to the verbal part of the particle verb and not to the complex verb + particle:

(19) a. prefix verb: downplay $\rightarrow$ [downplay]-ed

b. particle verb: play down $\rightarrow$ [play-ed] down (*[play down]-ed)

In the following, I adopt the assumptions about inflectional morphology formulated in Anderson's (1982, 1992) "Extended Word-and-Paradigm"-approach (see also Sadock 1985). According to this view, inflectional affixes are not represented in syntax. Syntactic heads carry morphosyntactic feature specifications, but the respective morphological modi-

5. I assume that PP-arguments of the particle verb are also generated to the right of the particle verb in English (possibly as complements of the particle inside the particle phrase). In contrast to NP-arguments, however, PPs do not need case. Therefore, even if the particle is a phrase, its PP-complement cannot move to the left and therefore always follows the particle:

(i) *John walked on Mary out 
fication of the word takes place at the interface to (or in) phonology. Inflectional morphology looks at the form of a word and its feature specification and then modifies the word form according to its paradigm. Typically, this modification entails the addition of an affix, but it may also involve a modification of the phonological form of the word, e.g. as the result of an Ablaut-rule.

The data in (18) and (19) suggest that the structure of particle verbs is always phrasal as far as inflection is concerned. If the particle verb could be a $\mathrm{V}^{0}$ with respect to morphology, we would expect that inflectional affixes could also attach to the whole particle verb. However, the fact that inflection always falls between the particle and the verb shows that morphosyntactic features ([-finite], [+past] etc.) are not inherited by the node that dominates the particle and the verb. This follows directly from the VP-analysis, according to which the particle is a phrasal complement of the verb and therefore irrelevant for the morphological operation that associates verbs with inflectional features.

But now we are facing a paradox. Even in those examples where the particle verb moves as a complex head, its inflectional properties mirror those of a phrasal construct (again, the fact that this paradox occurs in both English and Dutch suggests that it is appropriate to analyze particle verbs in these languages along the same lines):

$$
\begin{aligned}
& \text { John [looked up }]_{\mathrm{i}} \text { the information } \mathrm{t}_{\mathrm{i}} \\
& \text { omdat hij mij } \left.\mathrm{t}_{\mathrm{i}} \text { probeert [op te bellen] }\right]_{\mathrm{i}} \\
& \text { because he me tries Prt to ring } \\
& \text { 'because he tries to call me up' }
\end{aligned}
$$

According to what I argued in section 2.1, the movement properties of the particle verbs in (20) and (21) suggest that they are heads. However, the combination of the particle and the verb looks phrasal at the same time, because morphophonological rules associate inflection with the verb alone and not with the complex verbal head. The conclusion to be drawn is that the particle verbs in (20) and (21) must have the structures in (22):
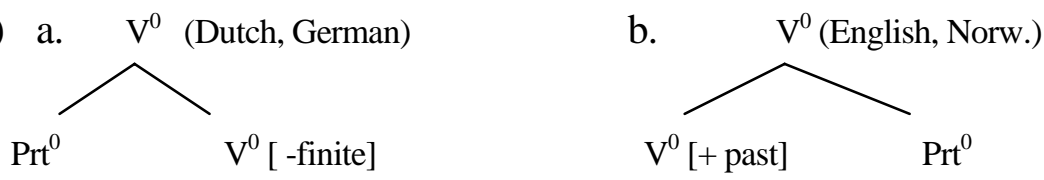

Although the particle verb is a head with respect to its ability to undergo verb movement, its internal structure resembles that of a phrase, since the morphosyntactic feature that determines inflection is only associated with the base verb and is not inherited by the complex $\mathrm{V}^{0}$-node. ${ }^{6}$

6. I depart here from the analysis of particle verb inflection that I suggest in Zeller (2001). There I assume that $z u$ and te are located in $\mathrm{Infl}^{0}$. (18) then follows from a phrasal analysis because only the base verb moves to $\mathrm{Infl}^{0}$ and combines with zu/te. However, notice that examples like (21) are hard to explain on the basis of a movement approach to inflection, since according to this idea, an inflected particle verb would correspond to an IP-node. But then it would be impossible to argue that the particle verb to the right of the matrix verb in (21) is a simple $\mathrm{V}^{0}$. I therefore consider the proposal that the inflectional features of a verb can be associ- 


\subsection{Verb movement to Comp}

The discussion in section 2.1 demonstrated that particle verbs can be represented both as phrases and as heads with respect to Verb Raising and particle shift. However, when the verb moves to Comp to derive the verb second (V2) order of declarative main clauses in languages like German, Dutch or Norwegian, particle verbs can never move as units; they are always separated ((23) is an example from German):
a. Peter steht auf Peter stands up
b. *Peter aufsteht Peter up-stands

Given my claim that grammar generally provides two structural ways of realizing a particle verb, there must be independent reasons that block the $\mathrm{V}^{0}$-option in the special case of verb movement to Comp. I suggest that these independent reasons have to do with the special inflectional properties of particle verbs dicussed in the previous section. Following a proposal made by Anderson (1993), I argue that complex verbs are only allowed in Comp if their top $\mathrm{V}^{0}$-node is associated with the verb's morphosyntactic specification.

As illustrated in section 2.2, Anderson $(1982,1992)$ treats inflectional morphology as being associated with lexical elements in morphophonology. Anderson (1993) argues that besides inflectional word-level morphology, there is also "inflectional morphology of phrases”. Like inflectional word formation rules, the rules of phrase-level morphology operate in phonology and may alter the representation of a phrase according to its morphosyntactic feature specification. The standard case of phrasal inflection is cliticization. Clitics, such as the English possessive affix 's, are "phrasal affixes" that are added in morphophonology as overt manifestations of a morphological rule that operates on phrases.

Importantly, Anderson analyzes V2 as being triggered by a rule of phrase-level morphology. Assuming that Tense, Mood and Agreement are components of the feature structure of a clause, he postulates the following rule, which can be seen as an inflectional rule of phrasal morphology (Anderson 1993, 88):

(24) Realize the inflectional features of a clause by (a) locating its first constituent, and (b) copying the features of Tense, Mood, and Agreement onto a word immediately following this anchor point.

Anderson regards (24) as a kind of "main clause complementizer" (expressing declarative mood), which, in contrast to complementizers in subordinate clauses, takes the form of a

ated with $\mathrm{V}^{0}$ even in the verb's base position to be an improvement, because it makes it possible to maintain the assumption that the inflected particle verb in (21) is a head. Notice that verbal inflection can still be taken to be a reflex of the presence of an Infl-node, as long as we assume that the respective morphosyntactic features of Infl can be transferred to the verb even if the verb has not moved to $\operatorname{Infl}^{0}$ (which seems to be a necessary assumption for English in any case). 
rule rather than of an overt element. The features mentioned in (24) are features of the clause, but they are realized as inflectional features of verbs. The morphological rule in (24) hence accounts for the V2-property of Germanic languages. The syntax must move the verb to Comp in order to place the inflectional features of the clause immediately after the first constituent (in SpecC). ${ }^{7}$

Anderson's proposal now yields a straightforward explanation for the fact that a particle verb cannot appear in Comp as a whole. As is illustrated by the structures in (22) above, a verbal head which represents the whole particle verb does not inherit the verb's inflectional properties, which is why inflectional affixes attach to the base verb and not to the whole particle verb. Therefore, if a verbal head consisting of the particle and the verb moved to Comp, (24b) would be violated, since the inflectional features of the clause could not be realized on a word (a head) following the first constituent of the clause. ${ }^{8}$

This means that although particle verbs in principle can be represented as heads and phrases, the fact that morphosyntactic features are never associated with the node dominating the whole particle verb renders the head-option unavailable in V2-contexts. The contrast between the behavior of particle verbs in V2 and their more liberal behavior in Verb Raising- or particle shift-constructions is a result of their special inflectional properties. (This, of course, still leaves open the question why the inflectional properties of particle verbs are special when the particle verb is a head.)

\subsection{Particle movement}

If a VP-representation of particle verbs is one of two possibilities, then the particle can be represented as a phrasal complement. As such, particles should be able to undergo XPmovement. In fact, the view that particles in German can be topicalized if they are part of a semantically transparent particle verb and allow for a contrastive interpretation (see (25b) and (26b)) is now widely accepted (cf. Lüdeling 1998; Wurmbrand 2000; Zeller 2001; Müller this volume). (27b) and (28b) show that directional particles in English also behave like full PPs with respect to topicalization or locative inversion constructions:

(25) a. Auf diesen Wagen wurde noch nichts geladen

on this cart was still nothing loaded

'Nothing has been loaded yet on this cart'

b. ?Auf wurde noch nichts geladen

on was still nothing loaded

'Nothing has been loaded up yet'

7. This idea requires additional assumptions about verb-first constructions in interrogative and imperative clauses. Anderson (1993) suggests in a footnote that those can be captured through comparable "Verb First" complementizer-rules.

8. Note that it is irrelevant whether the particle follows the verb, as in Norwegian, or whether it precedes the verb, as in German and Dutch. The complex head that includes the inflected verb and the particle never bears the inflectional features of the clause and hence violates (24b) regardless of the linear position of the particle with respect to the verb. 
(26) a. In dieses Land ist dieses Jahr noch niemand gereist into this country is this year still nobody travelled 'Nobody has entered this country this year'

b. ??Ein ist dieses Jahr noch niemand gereist in is this year still nobody travelled

'Nobody has entered (the country) this year'

(27) a. Up the road he went

b. Up he went

(28) a. Down the hill rolled the car

b. Down rolled the car

However, at least in German, the situation is in fact a bit more complicated. Notice that the examples with topicalized particles in (25b) and (26b) are slightly less than perfect. Many speakers consider them as highly marked or even ungrammatical. Judgements improve if the examples are embedded in an appropriate discourse context, but the fact that no context has to be provided in order to make the (a)-examples in (25) and (26) perfectly grammatical casts doubt on the assumption that particle phrases can move just like normal PPs.

This difference between particle phrases and normal PP-complements is even more evident in scrambling constructions. To my knowledge, it has not yet been noted in the literature on particle verbs that even those particles that can be topicalized can never be scrambled. Compare the examples in (25) and (26) with those in (29) and (30):

(29) a. weil auf diesen Wagen noch nichts geladen wurde

because on this cart still nothing loaded was

b. ?*weil auf noch nichts geladen wurde

(30) a. weil in dieses Land dieses Jahr noch niemand gereist ist because into this country this year still nobody travelled is

b. *weil ein dieses Jahr noch niemand gereist ist

In (29) and (30), scrambling has moved a phrase to a position after the complementizer weil and before the subject. This kind of movement (presumably adjunction to IP) is perfectly acceptable with full PPs, but ungrammatical with particles. This is a much stronger contrast than that in (25) and (26), where movement of particles, although slightly worse than movement of a PP, is still marginally acceptable.

The examples show that particles in German are less "mobile" than regular PPs. Note that this means that there is a clear difference between separability of particle verbs through verb movement and separability through particle movement. Whereas the verb always can move away from the particle in V2-, Verb Raising- and particle shift-constructions, moving the particle away from the verb yields questionable results in many cases. This casts doubt 
on the assumption that the phrasal representation of particle verbs looks exactly like that of a regular $\mathrm{V}^{0}+\mathrm{PP}$-complement construction.

Let me end this section by summarizing the crucial questions that have emerged from the discussion and which any theory of particle verbs must address:

(I) How can we represent the dual status of particle verbs (i.e. the fact that they can occur as heads and as phrases)?

(II) How can we capture the fact that the morphosyntactic feature specification of a particle verb looks like that of a phrase, even in contexts where the particle verb has undergone movement as a complex head?

(III) How can we explain that only particle verbs, but not other verb-complement constructions show the heterogeneous properties mentioned in (I)?

(IV) Why is movement of particles more restricted than movement of full PPs?

In section 3 I discuss questions (I) and (II) from different theoretical perspectives. An answer to question (III) is suggested in section 4, where I also discuss possible solutions to the problem raised by question (IV).

\section{Views from different perspectives}

\subsection{Incorporation}

Baker (1988) deals with examples like that in (31b), which shows Noun Incorporation in Greenlandic Eskimo:

(31) a. Sapannga-mik kusanartu-mik pi-si-voq bead-INSTR beautiful-INSTR $\varnothing$-get-INDIC3sS

b. Kusanartu-mik sapangar-si-voq beautiful-INSTR bead-get-INDIC3sS 'He bought a beautiful bead'

Example (31b) shows a derived complex verb sapangarsivoq which has all the properties of a morphological object and hence can be analyzed syntactically as a complex $\mathrm{V}^{0}$ derived by attaching the noun sapangar to the verbal stem -sivoq. Importantly, although this noun is part of the verb, it seems simultaneously to have independent status in syntax. As in (31a), where the noun is realized as an NP object of the verb, the modifier kusanartumik is licensed in (31b). This is surprising, since modifiers are usually part of a phrase (as specifiers or adjuncts), but they cannot modify a part of a word.

Baker explains data like (31) through a head-movement-analysis. He assumes that the noun sapangar projects an NP-complement of the verb in both (31a) and (31b). This NPrepresentation accounts for the presence of the adverb. Importantly, in (31b), the noun moves and incorporates into the verb, deriving a complex $\mathrm{V}^{0}$ and stranding the adverb: 


$$
\left[\mathrm{VP}\left[\mathrm{NP} \quad \mathrm{t}_{\mathrm{N}} \text { kusanartumik }\right] \quad\left[\mathrm{v}^{\circ}\left[\mathrm{N}^{\circ} \text { Sapangar }\right] \text { sivoq }\right]\right.
$$

Given my claim that particles can occur both as phrasal complements of the verb and as non-projecting parts of a complex $\mathrm{V}^{0}$, Baker's incorporation-analysis at first sight looks like a promising tool to analyze particle verbs. One could assume that the particle is always represented as a phrasal complement of the verb. The verb can move on its own, stranding the particle, but alternatively, the particle may incorporate into the verb, deriving a complex $\mathrm{V}^{0}$ which now can move as a unit:
a. $\left.\left[\begin{array}{lllll}{\left[\begin{array}{ll}p r t P & t_{p r t}\end{array}\right]} & t_{p v} & (\ldots) & {[\text { particle }} \\ \text { prt } & \text { verb }\end{array}\right]_{p v}\right]$
(SOV-language)

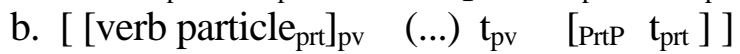
(SVO-language)

The alternation observed with particle verbs in Verb Raising-constructions as well as particle shift could now be explained by the idea that particles optionally incorporate into the verb. If incorporation takes place, the particle verb moves as a unit; if the particle does not incorporate, it is stranded when the base verb moves. Furthermore, according to the incorporation approach, the particle always projects a phrase. This explains why topicalization of particles is possible. Finally, the fact that the morphosyntactic features of the clause are realized as inflection on the base verb, and never on the whole particle verb, could be captured by assuming that these features are determined by the syntactic configuration before incorporation applies. At that stage, the particle verb is always a head-complement construction, and therefore, only the base verb bears inflectional features.

The incorporation approach also explains why full PPs cannot move together with the verb (see (8) and (9) above): Since only heads can incorporate, this option is not available for PPs. However, this explanation at the same time raises a serious problem. If particles can incorporate, why is this option not available for heads of transitive PPs (see Groos 1989 for similar criticism)?
a. *dat hij [pp $_{\mathrm{p}}$ Amsterdam] $\mathrm{t}_{\mathrm{i}}$ wilde $\left[\right.$ naar $_{\mathrm{p}}$ vliegen $_{\mathrm{i}}$ that he Amsterdam wanted to fly 'that he wanted to fly to Amsterdam'
b. *John $\left[\text { gave } \text { to }_{\mathrm{p}}\right]_{\mathrm{i}}$ the ring $\mathrm{t}_{\mathrm{i}}\left[\mathrm{t}_{\mathrm{p}}\right.$ Mary]

In (34), the heads of the PPs naar Amsterdam and to Mary have incorporated into the verb, stranding their complements. The complex verb consisting of the preposition and the verb has then undergone head movement. The incorporation approach does not explain why the results are ungrammatical. Notice that the same problem arises with respect to intransitive prepositions and adjectival resultative predicates. As heads, these elements would also be expected to incorporate into and move with the verb. However, as was shown in section 2.1, verbs with resultative- or intransitive PP-complements cannot move as complex verbs.

An even more serious problem for the incorporation approach is that it is precisely examples like (31b) that do not occur with particle verbs. Recall that particle phrases can be modified with adverbs. If the $\mathrm{V}^{0}$-representation of a particle verb was derived from a structure in which the particle projects a phrasal complement of the verb, it would be expected 
that these adverbs can also occur when the particle verb moves as a head. They should be stranded just like the adverb in (31b), which is left behind after noun incorporation. However, (35) shows that this is impossible.

(35) a. *dat Jan de bal [PrtP vlak $\left.\mathrm{t}_{\mathrm{prt}}\right] \mathrm{t}_{\mathrm{pv}}$ heeft $\left[\text { over }_{\mathrm{prt}} \text { geschoten }\right]_{\mathrm{pv}}$ that J. the ball right has over shot

b. *John [threw in $\left.{ }_{\mathrm{prt}}\right]_{\mathrm{pv}}$ the ball $\mathrm{t}_{\mathrm{pv}}\left[\right.$ right $\left.\mathrm{t}_{\mathrm{prt}}\right]$

The problem is that the incorporation approach predicts that there is always a particle phrase in syntax, even if the particle verb is a $\mathrm{V}^{0}$. However, as the examples of adverbial modification have shown, this does not seem to be the case. If the particle verb is a $\mathrm{V}^{0}$, then the particle is not phrasal, at least not with respect to the syntactic rules that license adverbial modification (recall that morphological rules still seem to "see" a phrasal structure of the particle verb, even if it is a head). What is needed is a theory that permits alternative representations of a particle verb without deriving one from the other by head movement.

\subsection{Parallel Morphology}

The idea that two terminal nodes $\mathrm{X}$ and $\mathrm{Y}$ can be represented syntactically by two alternative representations, one in which $\mathrm{X}$ and $\mathrm{Y}$ form a complex head and one in which $\mathrm{X}$ is the head of a phrasal XP-complement of Y, is central to Borer's $(1991,1993)$ theory of Parallel Morphology (PM). Borer (1993) is concerned with examples like (36):

(36) a. The (frequent) collection of mushrooms for six months finally gave rise to a heavenly meal

b. The collection was complete

In both sentences, a noun collection is derived by merging the verbal stem collect- with the derivational suffix -tion, which Borer assumes to be of category $\mathrm{N}$. The process derived nominal in (36a) refers to the event of collecting. In this reading, the internal argument of the verb is realized and adverbials like frequent can modify the singular form of the noun. In contrast, the result nominal in (36b) refers to the result of the collection. No arguments of the verb are possible and adverbials like frequent can only occur with the plural form of the noun.

According to Borer, the difference between (36a) and (36b) follows from a structural difference. She argues that the syntactic representation of collection in (36b) is that of a complex syntactic head. The verbal stem collect- is directly merged with the suffix -tion, which excludes internal arguments or modifiers that would force the verb to project. In contrast, Borer suggests that (36a) is derived from a basic representation in which collect- projects a VP which is the complement of the suffix -tion. This VP includes internal arguments and modifiers of the verb. Since the nominal head is an affix, the verb must undergo head movement and adjoin to -tion, but its VPprojection is still present syntactically and licenses the respective properties of the process 
nominal.

The PM-framework is attractive, because it explicitly allows the particle and the verb to appear in two different syntactic representations. One could argue that the phrasal representation of particle verbs corresponds to the structure of process nominals, the only difference being that the particle does not have to incorporate into the verb (because the verb is not affixal); the particle is therefore stranded when the verb moves. In the same way that process nominals co-occur with adverbs that modify the verb, the phrasal structure of particle verbs allows the particle to be modified. Alternatively, the particle verb can have the structure of a result nominal, in which case the particle verb can move as a complex head, but no adverbs are licensed. Since both structures are alternative representations, and not related to each other via head movement, the crucial problem illustrated by (35) with respect to the incorporation approach is avoided.

However, although the PM-approach to particle verbs is superior to the incorporationapproach in this respect, it fails to account for the inflection data. Recall that particle verbs always show the inflectional properties of a verb-complement construction, even if they are syntactically represented as heads. The PM-theory does not account for this situation; it rather predicts that particle verbs show two different inflectional patterns that correspond to the two structural representations. If the particle verb is a head, inflectional morphemes are now expected to precede the particle in Dutch and German and to attach to the particle in English and Norwegian. In section 2.2 I showed that this is never the case; inflectional affixes attach to the base verb.

In the PM-approach, the particle verb can be represented syntactically as a $\mathrm{V}^{0}$, but then, its phrasal representation is no longer accessible. However, the situation that also needs to be accounted for is that even if particle verbs are heads, morphosyntactic features are associated with the particle verb according to its phrasal representation. What we therefore need is a framework that combines the advantages of the incorporation- and the PM-approach. We need to be able to represent the VP- and the $\mathrm{V}^{0}$-structure of particle verbs as syntactic alternatives (as in PM), such that when the $\mathrm{V}^{0}$-structure is accessed by rules of verb movement, the VP-structure is invisible for syntax. At the same time, we want the $\mathrm{V}^{0}$ representation of particle verbs to be derived from the VP-structure (as in the incorporation approach) in such a way that the inflectional features of $\mathrm{V}^{0}$ are determined by the particle verb's phrasal representation. In the next section, I show how this complex state of affairs can be captured by a theory that allows for multiple-tree-representations.

\subsection{Autolexical syntax and reanalysis}

Sadock’s (1985) theory of “Autolexical Syntax" deals with mismatches between the morphological structure and the syntactic structure of a clause. Like Baker, Sadock discusses examples of Noun Incorporation from Greenlandic. In contrast to Baker, Sadock represents the dual status of nouns in these constructions not through head movement, but through two-sided diagrams in which the upper tree reflects the morphological structure of words, whereas the lower structure gives the syntactic representation of a clause. The simple example in (37) is represented through the diagram in (38): 
Hansi illu-qar-poq

Hans house-have-INFL

'Hans has a house'

(38)

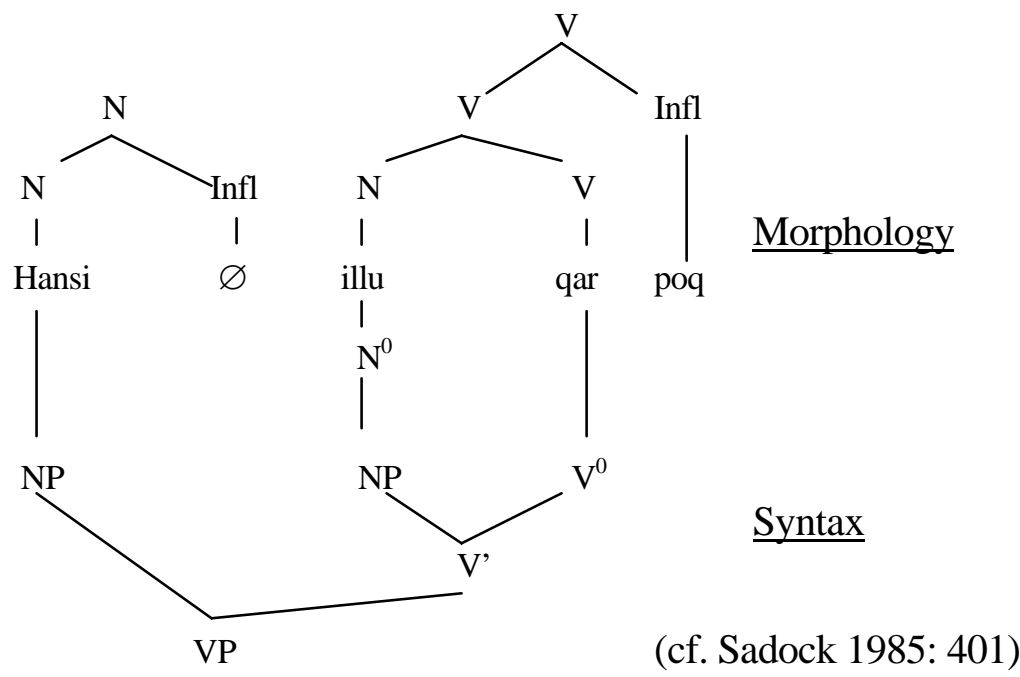

As in the example (31b) discussed above, the noun illu in (37) has the syntactic status of an $\mathrm{NP}^{9}$, but at the same time, it is part of the complex verb illuqarpoq. In Saddock's theory, this is represented through two separate trees which are linked to each other. In line with the view outlined in section 2.2, inflectional affixes are not represented syntactically and are added only at morphological structure.

Recall that we want to capture two facts: (i) particle verbs can alternatively be represented by two different structures with respect to syntactic movement, and (ii) only one of these structures determines the inflectional properties of particle verbs. Sadock's general idea seems quite useful - namely that a string of words can be represented through alternative trees that are relevant for different domains of grammar. It therefore seems promising to attempt an analysis of particle verbs by giving a diagram which includes two syntactic structures; one that represents particle verbs as verb-complement constructions and one that treats them as heads.

However, keep in mind that the tree in (38) is designed to deal with mismatches between morphology and syntax. Therefore, the two structures postulated by Sadock must be simultaneously available in order to explain that something can be both part of a complex word and part of a phrase. In contrast, as I pointed out in the preceding sections, the two structures of particle verbs are alternative syntactic representations. If the particle verb moves as a head, it is not also a VP, because adverbial modifiers would otherwise still be licensed. The only reflex of the phrasal structure of particle verbs which remains "visisble" when the particle verb is a head is the inflection of the base verb.

9. In the example in (37), the phrasal status of the noun is not evident, since no modifiers or possessors that indicate the presence of an NP are realized. 
Therefore, I suggest extending Sadock's multiple-tree diagram to accomodate the idea that the phrasal structure of particle verbs can optionally be mapped onto another syntactic structure which represents the particle verb as a head. Crucially, the morphosyntactic feature specification of the particle verb is determined by the phrasal structure but inherited by the derived head structure. I propose the following representation of the Verb Raising construction in (21) above; particle shift in English and Norwegian can be represented along the same lines (for reasons of space, I have omitted all nodes intervening between the particle verb-node in the infinitival clause and the matrix verb):

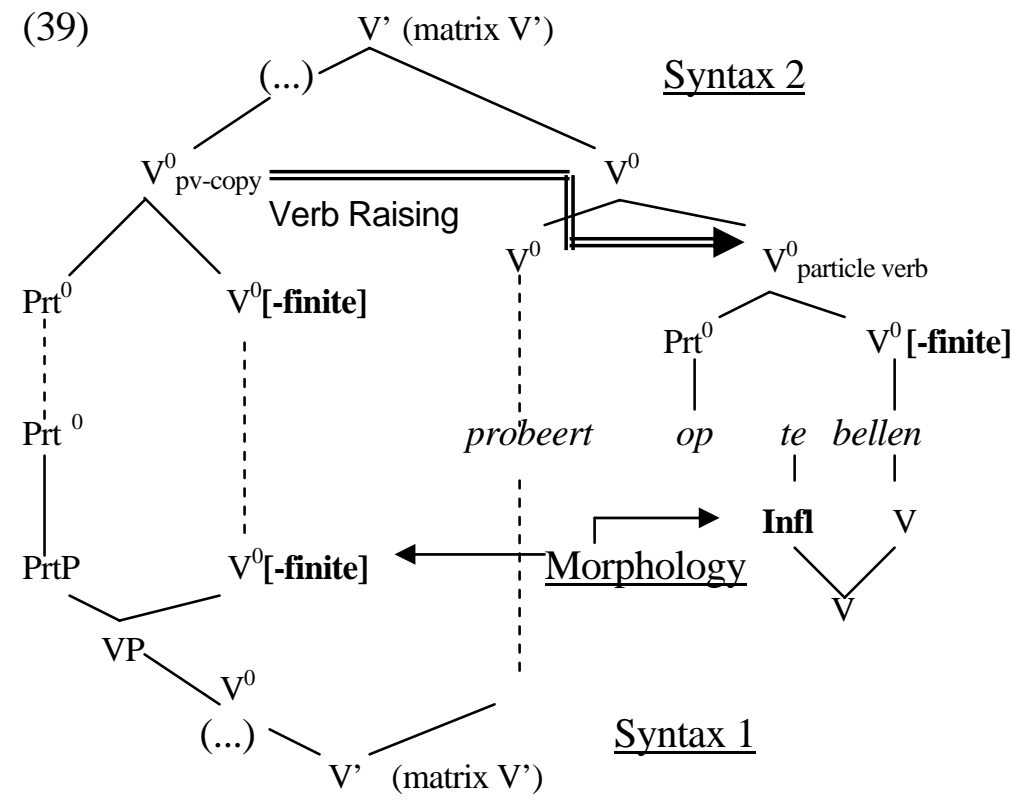

The tree in (39) exhibits two syntactic structures and the level of morphology. The lower level (syntax 1) is the phrasal representation of the particle verb opbellen. This structure is linked to the upper layer in (39) (syntax 2) where the particle and the verb form a $\mathrm{V}^{0}$. This $\mathrm{V}^{0}$ has undergone Verb Raising; the base position of the particle verb is represented as a copy. The terminal nodes of this copy $\left(\mathrm{Prt}^{0}\right.$ and $\left.\mathrm{V}^{0}\right)$ are linked to the respective terminal nodes of the particle verb in syntax 1 . In contrast to $\mathrm{Prt}^{0}$ in syntax 2, however, $\mathrm{Prt}^{0}$ in syntax 1 projects a phrase which combines with the verb as a complement.

The morphological component determines the morphosyntactic feature specification of the terminal nodes (according to their position in syntax) and the phonological spell-out of these features. ${ }^{10}$ Importantly, the relevant structure for the assignment of morphosyntactic features is the lower (phrasal) structure of syntax 1 . Since the particle is a complement in syntax 1, the feature [-finite] is associated with the base verb. Crucially, this feature is transferred to the base verb in syntax 2, although here the particle verb is a head. It is further transfered to the head-position of the particle verb chain. This copy of the particle verb is now linked to morphophonology (Sadock's morphological structure), where the infinitival

10. This view of morphology corresponds to the “distributed” morphology approach advocated by Halle \& Marantz (1993). 
prefix te is added to the base verb bellen, according to the morphosyntactic specification of the particle verb.

In (39), the syntactic properties of the particle verb are determined by the upper level. Therefore, movement triggers the whole particle verb. However, recall that syntax 1 and 2 are alternative representations of particle verbs. Therefore, the upper level of syntax 2 may also be absent from the diagram. In this case, the phrasal layer determines the syntactic properties of particle verbs, and only the base verb can undergo head movement, stranding the particle. Recall that this is the only available option in Dutch, German and Norwegian main clauses. Here, the inflectional features of the clause must be located in second position, but this requirement cannot be met by syntax 2, which would have to move the whole particle verb to Comp (see section 2.3). Notice furthermore that syntax 2 cannot be derived if syntax 1 includes an adverb. An adverb requires the presence of a particle phrase; therefore, it would not be licensed in syntax 2, since here the particle does not project.

The multiple-tree structure in (39) implements insights of both the incorporation- and the PM-approach. It shares with the former the idea that the head representation of particle verbs is derived from the VP-representation, which accounts for the unusual inflectional properties of particle verbs. However, it is similar in spirit to the latter, because the two representations of particle verbs are alternative syntactic structures. If the particle verb is a $\mathrm{V}^{0}$, syntax can no longer "use" the VP-structure from which it is derived. This explains why no modifiers of the particle are licensed when the particle verb is a head.

This proposal implies that the phrasal representation is somehow more basic than the head-representation of particle verbs. It seems that the $\mathrm{V}^{0}$-representation is merely an option, derived from the phrasal representation by merging the terminal nodes of the VP in such a way that the outcome is a complex head instead. Adopting the term traditionally used for cases where two syntactic trees are associated with one string of terminal nodes, I will henceforth speak of this process as reanalysis. If the particle verb is a $\mathrm{V}^{0}$, its basic verbcomplement structure has been reanalyzed as a complex head.

There is a crucial advantage of the idea that the head representation of particle verbs is derived from the phrasal one by reanalysis. If we make the reasonable assumption that reanalysis must preserve the linear order of terminal nodes (which means that there must be no crossing lines in tree diagrams like (39)), then it follows that the verb precedes the particle in SVO-languages like English, even if the particle verb is a $\mathrm{V}^{0}$. Normally, complex verbs like outswim or download in English obey the so-called Right-hand Head Rule (Williams 1981). If the $\mathrm{V}^{0}$-representation of the particle verb were formed by the same rule that forms these morphologically complex verbs, we would expect the particle to precede the verb. However, if we assume that the $\mathrm{V}^{0}$-representation is a reanalyzed VP-representation, then it follows that the linear order of particle and verb is still that of a verb-complement construction: since complements follow their verbs in SVO-languages, the particle must follow the verb even if the particle verb is a $\mathrm{V}^{0}$.

The following general picture emerges from the discussion. The basic representation of particle verbs is phrasal. This might be the result of the lexical syntactic structure of particles, which requires syntax to represent the particle node as being strictly head-governed by the verb (cf. Zeller 2001). Syntax therefore creates a structure that meets this lexical requirement (syntax 1), and the morphosyntactic features of the clause are associated with $\mathrm{V}^{0}$ 
according to this structure. Syntax 1 is now subject to the following reanalysis rule (adopted from Haegeman \& van Riemsdijk 1986: 420):

(40) Reanalyze $\alpha$, where $\alpha$ is a syntactic category.

(40) applies optionally. If the VP-node dominating the particle verb is subject to (40), the output of reanalysis is a syntactic structure different from syntax 1 (= syntax 2$)$ which represents the particle verb as a complex head. Syntactic rules like head movement now apply to this structure. Crucially, the reanalyzed structure inherits the morphosyntactic feature specification of syntax 1 . When syntax 2 is mapped to morphophonology, inflectional affixes are therefore associated with the base verb.

A general question that has to be answered concerns the conditions that govern the application of the rule in (40). Let us assume that (40) can only apply to a verb-complement construction if the verb's complement is a non-branching projection, which means that its head does not take any arguments. Given that it is not clear how these arguments could be accommodated in the reanalyzed structure, this seems a plausible condition on (40). It explains why the reanalysis of verbs and transitive PPs is excluded. However, I showed in section 2.1 that combinations of verbs and resultative predicates or intransitive PPs cannot move as complex verbs either. The question is why these constructions cannot be represented as complex $\mathrm{V}^{0} \mathrm{~s}$ as the result of the application of (40) - the respective VPs do not seem to be different from the phrasal structure of particle verbs. What is still needed is an account that explains why reanalysis cannot apply here. In the next section I try to provide such an account by showing that the structure of particle verbs differs from that of other head-complement constructions in a significant way. ${ }^{11}$

\section{Locality and extended projections}

According to Grimshaw (1991), the lexical projection LP of every lexical element L is selected by at least one functional head $\mathrm{F}$ of the same categorial type as $\mathrm{L}$ which determines L's “extended projection”. Phrasal complements of verbs are therefore normally functional projections. In Zeller (2001) I suggest that particle phrases are exceptional in this respect, because they are projections of lexical elements (prepositions, nouns, and a few adjectives) that do not have extended projections. Particles therefore always combine with the verb without an intervening functional head. I can only give a short illustration of the relevant arguments for this claim here, but see Zeller (2001) for further discussion.

11. Another important question raised by the reanalysis proposal concerns the place of the reanalyzed syntactic structure (syntax 2) in the architecture of grammar. The properties of particle verbs that motivated the postulation of this level show that reanalysis applies before movement. In terms of transformational syntax models that use multiple levels of syntactic representation (such as GB-theory), reanalysis can be assumed optionally to apply to the level of D-structure, deriving a representation which is then mapped onto Sstructure by the application of movement rules. It seems possible to also implement reanalysis in a purely derivational theory like Chomsky's (1995). However, it is difficult to accommodate the reanalysis proposal in a purely representational theory like the one developed in Brody's (1995), which only postulates one single level of syntax. 
Abney (1987) suggests that noun phrases should be analyzed not as simple NPs, but as $\mathrm{D}$ (eterminer)Ps. The NP-projection of the noun is the complement of a functional head $\mathrm{D}^{0}$. This head can be filled with a determiner, (41a), but may also be phonologically unrealized if the noun is a bare plural or a mass noun, (41b). Finally, in line with Postal's (1969) idea that pronouns are in fact definite articles, Abney suggests that pronouns are realizations of a functional head $\mathrm{D}^{0}$ without an NP-complement (cf. also Stowell 1991; Longobardi 1994), (41c):

(41) a. [DP [Dothe/a $\left.]\left[\mathrm{NP}_{\mathrm{N}}\left[\mathrm{N}^{\circ} \mathrm{Car}\right]\right]\right]$

b. [DP [D० Ø ] [NP [No cars/gold] ]]

c. $\left[D P\left[D^{\circ}\right.\right.$ she/him... ] ]

Now consider the examples in (42)-(44):

(42) a. omdat hij auto $\mathrm{t}_{\mathrm{i}}$ kan $[\text { rijden }]_{\mathrm{i}}$ because he car can drive

b. omdat hij $\mathrm{t}_{\mathrm{i}}$ kan [auto rijden] because he can car drive 'because he can drive a car'

(43) a. dat Jan piano $t_{\mathrm{i}}$ wil $[\text { spelen }]_{\mathrm{i}}$ that Jan piano wants play

b. dat Jan $t_{\mathrm{i}}$ wil [piano spelen] that Jan wants piano play 'that Jan wants to play the piano'

(44) a. dat wij plaats $\mathrm{t}_{\mathrm{i}}$ kunnen [nemen $]_{\mathrm{i}}$ that we place can take

c. dat wij $\mathrm{t}_{\mathrm{i}}$ kunnen [plaats nemen $]_{\mathrm{i}}$ that we can place take 'that we can take our seats'

As shown in (42)-(44), certain combinations of verbs and nouns in Dutch show the characteristic alternation observed with prepositional particle verbs in Verb Raising-constructions. In (42a), for example, only the verb has moved, stranding the noun auto, but in (42b), the noun has moved together with the verb. This alternation suggests that autorijden, piano spelen, and plaats nemen are nominal particle verbs, which can be represented as verbcomplement constructions or alternatively, as complex $\mathrm{V}^{0} \mathrm{~s}$ consisting of a verb and a noun.

Combinations like those in (42)-(44) are special in another important respect. As shown in (45), singular count nouns normally require a determiner in Dutch if they appear as phrasal complements (the same condition holds in German and English): 
(45) a. Jan koopt*(de) auto

Jan buys the car

b. Ik poets * (de) piano

I clean the piano

c. Ik reserveerde *(een) plaats

I reserved a place

'I reserved a seat'

However, as shown by (42)-(44) and in (46), nominal particle verbs are an exception to this rule. The noun phrases in (46) can combine with their respective verbs without a determiner:

(46) a. Jan rijdt auto

Jan drives car

b. Jan speelt piano

Jan plays piano

c. Ik neem plaats

I take place

Abney's (1987) DP-hypothesis provides an elegant way of accounting for the difference between (45) and (46). Suppose that only singular count noun $D P s$ must realize $\mathrm{D}^{0}$ obligatorily with an overt determiner. Then the occurrence of the determiner-free noun phrases in (46) can be explained by assuming that the nouns are in fact bare NPs without an extended projection, such that the condition applying to (45) does not apply to them. On this view, the phrasal representation of a nominal particle verb is a V+NP-structure. It contrasts with verb-complement constructions like those in (45), which are combinations of a verb and a DP-complement.

It is widely assumed that there is a correspondence between the referential interpretation of a phrase and functional structure. Only DPs can be referential, NPs never can (cf. Stowell 1991; Longobardi 1994). Since nominal particles are NPs, it is predicted that they can never refer. This prediction is realized by the constructions in (42)-(44) and (46) - in contrast to the DPs in (45), the NPs in these examples are interpreted generically; they express types, not tokens. With this observation in mind, let me now turn to prepositional particle phrases.

Van Riemsdijk (1990) and Koopman (1993) argue that PPs also have extended projections. Van Riemsdijk assumes that in German, the functional head that selects a lexical PP and projects a functional prepositional phrase $\mathrm{FP}_{\text {prep }}$ can be realized overtly by a postpositional element, (47a). Furthermore, in the same way as the D-head of a DP can remain phonologically unrealized (see (41b)), the functional head of the preposition's extended projection can be invisible. Transitive and intransitive prepositional phrases are therefore analyzed as $\mathrm{FP}_{\mathrm{prep}} \mathrm{S}$ with phonologically unrealized functional heads, (47b) and (47c). Finally, there are also prepositional proforms; i.e. $\mathrm{FP}_{\text {prep }}$ which are projections of a functional head without a PP-complement. (47d) shows that postpositions like herein or hinaus can function as prepositional proforms. Traditional grammars refer to them as "pronominal adverbs": 
(47)
a. [FP [pp aus dem Haus] [Fo hinaus ] ]
'out of the house (out)'
b. [FP [pp aus dem Haus] [F॰ Ø] ]
'out of the house'

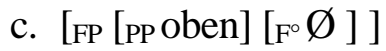
d. [FP [Fo hinaus ] ]
'upstairs'
'out'

Jackendoff (1983) argues that prepositional elements, like nouns, can be distinguished according to their ability to express tokens or types, i.e. they can be referential or nonreferential. Now recall that I argued that a prepositional particle phrase is a bare PPcomplement of the verb. The aforementioned assumption that only functional phrases can be referential and express tokens predicts that particle phrases are never referential. This prediction is realized, as observed by McIntyre (2001). Compare the prepositional phrases in (48):

(48) a. Peter lädt die Koffer [Fp [pp in das Auto ] Ø] ti

b. Peter lädt $t_{\mathrm{i}}$ die Koffer [FP [pp in das Auto] hinein] $\mathrm{t}_{\mathrm{i}}$ Peter loads the suitcases in the car (in)

'Peter is loading the suitcases into the car'

c. Peter lädt $\mathrm{t}_{\mathrm{i}}$ die Koffer [FP [Fo hinein] ] $\mathrm{t}_{\mathrm{i}}$

d. Peter lädt $\mathrm{i}_{\mathrm{i}}$ die Koffer [pp [po ein]] $\mathrm{t}_{\mathrm{i}}$ 'Peter is loading the suitcases (into something)'

In (48a-c), functional prepositional phrases are generated as complements of the verb laden, 'load' (which has moved to Comp). The Path-concept expressed by these directional $\mathrm{FP}_{\text {prep }} \mathrm{S}$ is referential in all three examples - the Theme die Koffer traverses a specific Path into a specific place.

The referentiality of the Paths expressed in (48a) and (48b) is not surprising, since here, the reference object (the Goal das Auto) is explicitly mentioned as the internal argument of the preposition in inside the PP. However, the prepositional proform hinein in (48c) has an implicit reference object ${ }^{12}$, but still expresses a Path-token. Given that the Goal is implicit, the specific Path-token must be identified on the basis of contextual information about the Goal. (48c) can therefore only be uttered felicitously if the discourse allows the hearer to identify a particular place (like e.g. a specific car parked outside the house) as the Goal into which the Theme is loaded. As with free pronouns, contextual information is required to establish the reference of the proform hinein.

Like hinein, the prepositional particle ein in (48d) has an implicit reference object. However, there is an important contrast between (48c) and (48d). The particle in (48d) expresses a non-specific type of Path. Consequently, the reference of the implicit Goal of the particle ein is not contextually given. For example, if a speaker utters (48b), it may not be clear at all into what place exactly the suitcases are loaded. The relevant information here is only that they are loaded into something, but the Goal, and therefore the whole Path, remain non-

12. A postposition like hinein inherits the thematic structure of the basic preposition from which it is derived. Therefore, hinein, like the preposition in, has a Theme and a Goal-argument. In contrast to prepositions, however, the reference object of a postposition cannot be expressed by a DP, but only by a PP-complement. If no PP is present, as in (48c), it remains implicit. See Zeller (forthcoming) for semantic details. 
specific. If the assumption that lexical projections can never be referential is adopted, then the semantic difference between (48c) and (48d) follows nicely from my proposal that particle phrases differ from "regular" phrases in lacking an extended projection. Since a referential interpretation is only available if functional structure is present, it follows that particles like ein in (48b) can only express non-referential Path-types.

The consequence of assuming that particle phrases lack extended projections is that even if particle verbs are represented as verb-complement constructions, the relation between a particle and its base verb is strictly local. In contrast, if the complement of a verb is a functional projection, its functional head destroys the local relation between the verb and the lexical head $\mathrm{L}$ of the complement. ${ }^{13}$ I now suggest that the answer to the question raised at the end of section 3.3 can be given on the basis of this observation. I assume that the possibility of reanalyzing the terminal nodes of a head-complement-construction is restricted to terminal nodes that establish a local domain.

This assumption immediately explains why only the VP-structure of particle verbs can be reanalyzed and be represented as a complex $\mathrm{V}^{0}$. The kind of reanalysis that was illustrated in (39) in section 3.3 through a separate tree structure is not possible with heads of phrases which are separated from the verb through a functional head. This means that VPs that consist of e.g. verbs and projections of intransitive prepositions do not permit reanalysis. As I suggested in (47c) above, intransitive prepositions also have extended projections. Therefore, an (empty) functional head intervenes between the intransitive preposition and the verb and consequently, the two terminal nodes of the preposition and the verb cannot be reanalyzed as a $\mathrm{V}^{0}$.

Notice that resultative predicates also have extended projections. Evidence is provided by the Norwegian examples in (49), which show that resultative adjectives are inflected: ${ }^{14}$

$$
\begin{aligned}
& \text { a. Vi vaska golvet reint } \\
& \text { we washed the.floor-SG-N clean-N } \\
& \text { b. *Vi vaska golvet rein } \\
& \text { we washed the.floor-SG-N clean } \\
& \text { 'We washed the floor clean' }
\end{aligned}
$$

(Åfarli 1985: note 8)

I assume that agreement between the resultative adjective and the object is mediated through the adjective's extended projection (which can be analyzed as a Small Clause or a comparable construction). The head of this functional projection intervenes between the resultative adjective and the verb and hence prevents the two heads from being reanalyzed.

13. As already indicated in section 3.3, this local relation can be expressed in terms of government, such that particles are lexical heads that are strictly head governed by the verb. For all other lexical heads, the functional head of their extended projection constitutes a minimality barrier.

14. Given that inflectional affixes are not present in syntax, but only added in morphophonology, (49) does not present a conclusive argument for the view that resultative predicates have extended projections. However, I assume that even though functional heads do not necessarily host inflectional affixes, they nevertheless determine the morphosyntactic feature specification of the lexical heads in their extended projection (which then triggers the choice of inflectional morphology). On this assumption, the inflection of the adjective in (49a) is a reflex of the presence of a functional head. 
Finally, let me address question (IV), stated at the end of section 2, which concerns the problematic status of particle phrases with respect to movement. I have argued in this section that particle phrases are syntactically "impoverished" and that particle verbs establish a local domain even if the particle is a phrase. I assume that this situation is the main reason for the problematic behavior of particle phrases with respect to movement. Due to the complexity of the data, I cannot present a comprehensive account here, but let me offer some discussion of how a proposal based on this idea could look.

One possibility would be to argue that the absence of an extended projection binds a particle phrase closer to the verb than it is the case with other phrasal complements. Notice that the local relation between a verb and a particle gives rise to strong mutual dependencies. Particles and verbs often license special meanings of each other. Many particles are ambiguous, with particular meanings occuring only with particular (classes of) base verbs. At the same time, certain verbs or verb meanings are only licensed in the context of a particle (see Zeller 2001 for detailed discussion). Now suppose that if a particle moves away from its verb, the respective licensing relations no longer can be established. It would follow from this assumption that only if the particle is semantically relatively independent and highly productive (in the sense that its semantics does not depend on the presence of a particular verb) can it be topicalized.

An obvious question raised by this idea is why verb movement does not yield the same problems as particle movement. Why can the verb still license (or be licensed by) a particle if it has moved away? In the multiple-tree diagram in (39) in section 3.3, I represented the "trace" of head movement as a copy. The copy theory of movement explains why the local relation between $\mathrm{Prt}^{0}$ and $\mathrm{V}^{0}$ is preserved within VP, even if the base verb undergoes head movement. However, representing a topicalized particle phrase as a copy in its base position would have the same preservation effect. In order to make the proposal work, one therefore would have to show that the status of head movement with respect to reconstructability of lexical relations is different from the status of XP-movement. ${ }^{15}$

An alternative account, which offers a straightforward explanation for the contrast between particle movement and verb movement, would be to assume that XP-movement is generally more restricted with non-functional phrases. The general idea would be that it is only through their extended projections that phrases can become fully accessible for syntactic rules. One would have to incorporate into this proposal the claim that, although XP-

15. There is in fact independent evidence that verb movement does not affect the licensing of special meanings in the way phrasal movement does. Although phrasal parts of VP-idioms in German are often immobile and cannot be topicalized, no idiomatic interpretation ever prevents the verb from moving to Comp in V2, cf.:

(i) a. Er malt den Teufel an die Wand

he paints the devil on the wall

'He tempts fate'

b. *An die Wand malt er den Teufel 
movement of lexical projections is not entirely excluded, it is only possible under certain conditions, namely if it is licensed by a specific contrastive context or discourse.

There are several questions that still remain. One general question has to do with the difference between particle topicalization in German and in English. I showed in section 2.4 that even when a contrastive reading is available, particle topicalization in German is often highly marked. However, there seems to be no comparable difference in acceptability between fronted PPs and fronted (directional) particles in English. Another question concerns the difference between particle topicalization and scrambling. Although the special status of particle verbs might explain why neither of the two movement operations yields perfectly grammatical results in German, it leaves open the question why scrambling of contrastive particles is still considerably worse than topicalization.

I do not attempt to offer an answer to these questions here, since this requires a comparison of a much wider range of data from particle movement. However, the crucial observation made in section 2.4 is that there is a contrast between regular prepositional phrases and particle phrases with respect to movement. According to the analysis presented in this section, a regular prepositional phrase is an $\mathrm{FP}_{\text {prep}}$, whereas a particle phrase is a $\mathrm{PP}$. This is a structural distinction between two kinds of complements of the verb which is not offered by any other theory on particle verbs. It therefore provides a suitable starting point for an analysis of the contrasts observed in section 2.4.

\section{Conclusion}

Most studies on particle verbs either focus on the properties of this construction in SVOlanguages like English or Norwegian or on the properties of particle verbs in SOVlanguages like Dutch and German. In this article, I have sought to present a more general approach by highlighting the similarities between these languages with respect to the way they realize particle verbs. Furthermore, whereas the debate concerning particle verbs is often characterized by a controversy between those who argue that they are heads and those who assume that they are phrases, I have argued here that there are in fact two alternative ways of representing particle verbs in syntax: they can occur as complex heads and as phrasal constructions. I tried to show that on the basis of this account, the verb-particle construction in languages like English, Dutch or German can receive a uniform treatment. Typological differences follow from independent, language- or language-type-specific properties, like the SOV/SVO-parameter or the V2-property.

\section{References}

\footnotetext{
Abney, Steve

1987 The English Noun Phrase in Its Sentential Aspect. Ph.D. dissertation, Massachusetts Institute of Technology, Cambridge.

1985 Norwegian Particle Constructions as Causative Constructions. Nordic Journal of Linguistics 8: 7598.
} 
Anderson, Stephen R.

1982 Where's Morphology? Linguistic Inquiry 13: 571-612.

Anderson, Stephen R.

1992 A-Morphous Morphology. Cambridge: Cambridge University Press.

Anderson, Stephen R.

1993 Wackernagel's Revenge: Clitics, Morphology, and the Syntax of Second Position. Language 69, 6898.

Baker, Mark

1988 Incorporation. A Theory of Grammatical Function Changing. Chicago/London: The University of Chicago Press.

Baltin, Mark R.

1989 Heads and Projections. In: Mark Baltin and Anthony Kroch (eds), Alternative conceptions of phrase structure. The University of Chicago Press, Chicago, 1-16.

Borer, Hagit

1991 The Causative-Inchoative Alternation: A Case Study in Parallel Morphology. The Linguistic Review 8: 119-158.

Borer, Hagit

1993 Derived nominals. Ms., University of Massachusetts, Amherst.

Brody, Michael

1995 Lexico-Logical Form. MIT Press, Cambridge.

Chomsky, Noam

1995 The Minimalist Program. Cambridge: MIT Press.

Dikken, Marcel den

1995 Particles. On the Syntax of Verb-Particle, Triadic, and Causative Constructions. New York/Oxford: Oxford University Press.

Evers, Arnold

1975 The Transformational Cycle in Dutch and German. Ph.D. dissertation, University of Utrecht/Indiana University Linguistics Club.

Grimshaw, Jane

1991 Extended Projections, Ms., Brandeis University.

Groos, Anneke

1989 Particle-verbs and adjunction. In Hans Bennis and Ans van Kemenade (eds), Linguistics in the Netherlands 1989: 51-60.

Haegeman, Liliane and Henk van Riemsdijk

1986 Verb Projection Raising, Scope, and the Typology of Rules Affecting Verbs. Linguistic Inquiry 17, 417-466.

Halle, Morris and Alec Marantz

1993 Distributed Morphology and the Pieces of Inflection. In: Ken Hale and Sam Keyser (eds.), The View from Building 20, Cambridge: MIT Press: 111-176.

Jackendoff, Ray

1983 Semantics and Cognition. Cambridge: MIT Press.

Johnson, Kyle

1991 Object Positions. Natural Language and Linguistic Theory 9: 577-636.

Koopman, Hilda

1993 The structure of Dutch PPs, Ms., University of California at Los Angeles.

Larson, Richard

1988 Light Predicate Raising. MIT Cognitive Science Center Working Papers. MIT, Cambridge.

Longobardi, Giuseppe

1994 Reference and Proper Names: A Theory of N-Movement in Syntax and Logical Form. Linguistic Inquiry 25: 609-665.

Lüdeling, Anke 
1998 On Particle Verbs and Similar Constructions in German. Ph.D. dissertation, University of Stuttgart. McIntyre, Andrew

2001 German double particles as preverbs: Morphology and Conceptual Semantics. Tübingen: Stauffenberg.

Müller, Stefan

this volume

Syntax or morphology: German particle verbs revisited.

Neeleman, Ad

1994 Complex predicates. Ph.D. dissertation, Utrecht University.

Neeleman Ad

this volume

Particle placement.

Postal, Paul M.

1969 On so-called 'pronouns' in English”. In D. A. Reibel and S. A. Schane (eds), Modern Studies in English. Englewood Cliffs: Prentice-Hall, 201-224.

Riemsdijk, Henk van

1978 A Case Study in Syntactic Markedness. Dordrecht: Foris.

Riemsdijk, Henk van

1990 Functional Prepositions. In: H. Pinkster and I. Genée (eds.): Unity in Diversity. Dordrecht: Foris: 229-241.

Sadock, Jerrold M.

1985 Autolexical Syntax: A proposal for the treatment of Noun Incorporation and similar phenomena. Natural Language and Linguistic Theory 3, 379-439.

Stowell, Tim

1991 Determiners in NP and DP. In: Katherine Leffel and Denis Bouchard (eds.), Views on Phrase Structure. Amsterdam: Kluwer Academic Press: 37-56.

Svenonius, Peter

1996 The Verb-Particle Alternation in the Scandinavian Languages. Ms., University of Tromsoe.

Williams, Edwin

1981 On the Notions 'Lexically Related' and 'Head of a Word'. Linguistic Inquiry 12: 245-274.

Wurmbrand, Susi

2000 The structure(s) of particle verbs. Unpublished manuscript, University of Montreal.

Zeller, Jochen

2001 Particle verbs and local domains. Amsterdam: John Benjamins

Zeller, J. (to appear).

forthcoming Lexical particles, semi-lexical postpositions. In: Norbert Corver and Henk van Riemsdijk (eds), Semi-lexical categories. Berlin and New York: de Gruyter. 